\title{
Rapid determination of some trace metals in several oils and fats
}

\author{
By Farooq Anwar ${ }^{* 1}$, T.G.Kazi ${ }^{3}$, Rubina Saleem ${ }^{2}$ and M.I.Bhanger ${ }^{3}$ \\ ${ }^{1}$ Department of Chemistry, University of Agriculture, Faisalabad-38040, Pakistan. \\ Ph: +92-41-9200161-67, Ext.3309. Fax: +92-41-601587. E-mail: fanwarpk@yahoo.com \\ ${ }^{2}$ PCSIR Labs. Complex, Karachi-75280, Pakistan \\ ${ }^{3}$ Center of Excellence in Analytical Chemistry, University of Sindh, Jamshoro, Pakistan.
}

\section{RESUMEN} grasas.

Determinación rápida de trazas metálicas en aceites y

Se ha establecido un método analítico rápido mediante espectroscopia de absorción atómica para determinar con rapidez trazas metálicos en algunos aceites y grasas. Las muestras se preparan mediante una técnica extractiva que utiliza ultrasonidos. Los parámetros del análisis han sido optimizados para mejorar la recuperación de metales a niveles de ultra-traza en el menor tiempo posible. El uso de ultrasonidos, seguido por centrifugación para la separación de fases, redujo el tiempo convencional de extracción de 180 na $10 \mathrm{~min}$. Los rangos de recuperación de hierro, cobre, níquel y zinc fueron $94.6-98.0 \%$, 93.6-100.4\%, 95.0-97.3\% y 96.0-101.2\%, respectivamente, cuando se utilizó un aceite de soja fortificado con $0.10,0.25,0.50,0.75,1.00 \mathrm{mg} / \mathrm{gm}$ of cada metal utilizando el método estándar de adición. Los rangos de recuperación de los metales fueron muy similares a los obtenidos mediante el método de digestión húmeda. En la mayor parte de las muestras de aceites y grasas analizadas se encontraron cantidades significativas de hierro y níquel que oscilaron entre $0.13-2.48 \mathrm{ppm}$ y $0.027-2.38 \mathrm{ppm}$, respectivamente, mientras que los contenidos de cobre y zinc oscilaron entre $0.01-0.15$ ppm y 0.03- $0.21 \mathrm{ppm}$, respectivamente.

PALABRAS-CLAVE: Aceites vegetales - Centrifugación Extracción ácida - Trazas metálicas - Ultrasonidos.

\section{SUMMARY}

Rapid determination of some trace metals in several vegetable oils and fats.

An atomic absorption spectrophotometric method has been devised for the rapid determination of trace metals, found in several vegetable oils and fats. Samples were prepared using an ultrasonically assisted acid-extractive technique. The parameters of the analysis were optimized to improve the recovery of metals from the oil matrixes at an ultra trace level within the least possible time. The use of ultrasonic intensification, followed by centrifugation for phase separation reduced the conventional acid extraction time from 180 to only 10 minutes. The respective range of recovery of iron, copper, nickel and zinc was found to be $94.6-98.0 \%, 93.6-100.4 \%$, $95.0-97.3 \%$ and $96.0-101.2 \%$ in a soybean oil which was fortified with $0.10,0.25,0.50,0.75,1.00 \mathrm{ug} / \mathrm{gm}$ of each of the metals using the standard addition method. The ranges of recovery of these metals as investigated by the proposed method were also found in close agreement with those of the wet digestion method. Most of the samples of commercial oils and fats were found to be contaminated with notable amounts of iron and nickel ranging from $0.13-2.48$ and $0.027-2.38 \mathrm{ppm}$ respectively. The contents of copper and zinc were also high in many brands, ranging from $0.01-0.15 \mathrm{ppm}$ and zinc 0.03 $0.21 \mathrm{ppm}$ respectively, which poses a threat to oil quality and to human health.
KEY-WORDS: Centrifugation - Improved acid-extraction - Trace metals -Ultrasonic intensification - Vegetable oils.

\section{INTRODUCTION}

The presence of small amounts of trace metals in oils and fats is known to produce deleterious effects on quality. The strongest and most notable proxidants are copper and iron, which produce a noticeable oxidative effect at concentrations as low as 0.005 and $0.03 \mathrm{ppm}$ respectively (Black et al., 1975; Marfec et al., 1997; Persmers et al., 1971). Some metals e.g., nickel, zinc, copper, cadmium and lead are important from a health and safety stand point, as linked either directly or indirectly via cholesterol levels to coronary heart disease (Elson et al., 1981; Ivanov et al., 1995).

The determination of metals in vegetable oils and fats has been under investigation for several years and is still a formidable problem. Several methods for this analysis, including atomic absorption spectrophotometry (AAS) have been published in the literature (Anzan et al., 2000; Elson et al., 1981; Flider et al., 1981; Hammond et al., 1998; McGinley, 1991; Persmers et al., 1971; Sleeters, 1985). AAS has gained wide acceptance in these determinations because of its practical advantages, relatively high sensitivity, and analytical accuracy. Most of the methods for the analysis of metals in oil matrixes that could be coupled to AAS are generally preceded by time taken and tedious heat destruction procedures, e.g., digestion and high temperature ashing, before the metals are available for quantification.

There is no universal ashing procedure for all metals because of their reactivates and volatilities, and the technique may yield low results owing to the volatilization of specific metals (Black et al., 1975), which is most often of interest in this field. The direct aspiration of oil diluted with methyl isobutylketone (MIBK) plus flame AAS, and dilution with iso-amyl acetate plus flameless AAS under oxygen (Elson et al., 1981) has proved successful to some extent. However, the major drawback, encountered with these techniques is the dilution factor, which reduces 
the metal content per unit volume (Flider et al., 1981). Some analytical protocols in this field included the determination of copper in edible oils by direct graphite furnace AAS (McGinley, 1991; Chen et al., 1999). Chen et al., (Chen et al., 1999) developed a simple method for the determination of copper in edible oils, using a polarized Zeeman graphite furnace atomic absorption spectrophotometer and a pyrographite tube. The method involved dilution of oils with $2 \%$ lecithin-cyclohexane and direct analysis by standard addition method. Allen et al., (Allens et al., 1998) reported plasma and furnace atomic spectroscopies in which an atomic pressure microwave digestion procedure is described for the determination of copper, lead and nickel in edible oils. Another method proposed by Yaman et al., (Yaman et al., 1998), involved the determination of nickel in vegetable matrixes by AAS, after pre-concentration on activated carbon.

Among the simpler atomic absorption spectroscopic methods requiring minimal manipulation and lowest probability of sample contamination, solubilizing and extraction of total trace metals from oil matrixes have also been used over the years (Flider et al., 1981; Persmers et al., 1971). Conventional acid extraction as reported in the literature (Chmilenko et al., 1998), is time consuming (takes approximately 180 minutes) although the method is adequate to confirm the wet digestion results (Chmilenko et al., 1998; Elson et al., 1981). The lower efficacy of the conventional extraction procedure in extracting some metals suggested that a portion of these metals was either tightly bound to the constituents of oils, or else existed in a form, such as organometallic compound, which has a high affinity for the oil phase (Elson et al., 1981). It is assumed that under the normal mode of extraction, many of the metals could not be quantitatively recovered from the oil as it failed to intensively break and separate the molecules of oil matrix to free the bound metals into the aqueous phase.

The interest for modifications and improvements in the existing acid-extraction procedures for the analysis of trace metals by AAS has existed for years. Using an acid-extractive technique, Price et al., (Price et al., 1970) outlined an atomic absorption method for the rapid determination of nickel in edible fats. Ivanov et al., (Ivanov et al., 1994) developed a rapid method for the differentiated determination of ion dissociated; ion bound and covalent bound heavy metals in lipids, by the extractive separation of bound and dissociated ions, followed by mineralization of the residue to determine the covalent bound heavy metals by spectrophotometry. Presently, the use of ultrasonic intensification in the preparation of samples for the rapid determination of trace metals in oil and fat products is gaining importance. Chmilenko et al., (Chmilenko et al., 1998), using the ultrasonic intensification of sample preparation, proposed a method for the rapid determination of lead, copper and cadmium in fats and oils.

In our preliminary work (Anwar et al., 2001), we had reported a simple acid-extraction method, for the estimation of trace metals in vegetable oils and fats. The present research was directed, further, to devise an improved acid-extraction procedure for the rapid determination of the most relevant metals. Within the framework of optimized conditions, set forth in the present work, this was better performed with the use of ultrasonic intensification and the proposed method was successfully applied for the accurate determination of iron, copper, nickel and zinc in a series of oil and fat composites.

\section{MATERIALS AND METHODS}

\subsection{Product selection}

Three separate samples (with different code and batch number), in duplicate, of each brand/company for each of the banaspati, cooking oils, shortenings and margarines were obtained at local retail outlets (designated as company codes). Margarines oils were recovered by melting the samples in acid-washed beakers on a hot plate, allowing phase separation at $95-100{ }^{\circ} \mathrm{C}$ in an oven, overnight. The decanted oil layer was dried on a rotary evaporator at $90{ }^{\circ} \mathrm{C}$ for 1 hour and finally, decanting the clear oil from the top of the material.

\subsection{Reagents and glassware}

Sulphuric acid, nitric acid, carbon tetrachloride and hydrogen peroxide were analytical reagentgrade from E. Merck. All glassware, cleaned with 1:1 $\mathrm{HNO}_{3}$ was used through out the work. Standard solutions of iron, copper, nickel and zinc were prepared using the dilution of certified standard solutions (1000ppm, Fluka Kamica) of corresponding metal ions.

\subsection{Apparatus}

A Sonicor, Model No. SC-121TH, Sonicor Instrument Corporation Copiague, N.Y, USA with technical specifications; timer 0-30 minute, volts 220 , cycles $50 / 60 \mathrm{HZ}$, was used for the purpose of ultrasonic intensification. Centrifugation was carried out using a WIROWKA Laboratoryjna type WE-1, nr6933 centrifuge; speed range 0-6000 rpm, timer 0-60 minutes, 220/50HZ, Mechanika Phecyzyjna, Poland. A Hitachi Ltd., Model 180-50, S.N.5721-2 Atomic Absorption Spectrophotometer with a deuterium lamp back corrector, linear (least square) mode, and equipped with a Hitachi Model 056 recorder was 
used for recording analytical data of the metals under investigation.

\subsection{Methods of analysis}

The oil or fat samples were stored in a refrigerator, melted in a water bath and mixed thoroughly before sampling. Samples were prepared for analysis by wet digestion (acid digestion) and by improved acid extraction methods.

\subsubsection{Wet digestion:}

Duplicate samples $1.0 \mathrm{~g}$ were weighed into separate conical flasks. $5 \mathrm{~mL}$ of concentrated nitric acid was then added and the contents heated at $70-80^{\circ} \mathrm{C}$ for $2-3$ hours, on a hot plate. Heating was continued at about $150{ }^{\circ} \mathrm{C}$ overnight, $3-5 \mathrm{~mL}$ of concentrated sulphuric acid and 30\% hydrogen peroxide (each) was added occasionally and continuous heating further allowed to completely decompose the organic matter, until obtaining clear solutions. All contents of the flasks were evaporated and the semidried mass was dissolved in a small amount (approx. $5 \mathrm{~mL}$ ) of deionized water, filtered through Whatman \# 42 paper, and made up to a final volume of $25 \mathrm{~mL}$ in volumetric flasks with $2 \mathrm{~N}$ nitric acid.

\subsubsection{Improved acid-extraction:}

Replicate $5.0 \mathrm{~g}$ samples were diluted with $10 \mathrm{~mL}$ of carbon tetrachloride and then extracted with 10 $\mathrm{mL}$ of $2 \mathrm{~N}$ nitric acid by subjecting the samples to ultrasonic intensification. The samples were allowed to intensify separately for time periods of $2.50,4.0$, $5.50,7.0,9.0,12.0,15.0$ minutes. The resulting mixtures were poured into separating funnels and allowed to equilibrate under refrigeration for different time periods of $5.0,10,20,30,40,50,60$ minutes and overnight. In another set of identical treatments, the organic and aqueous phases were separated by centrifugation of the resulting mixtures for time intervals of $1.0,1.5,2.0,2.5,3.0,3.5$ and 4.0 minutes at $2500 \mathrm{rpm}$, where the mixtures underwent a relative centrifugal force (RCF) of $628.87 \mathrm{~g}$. The portions of upper aqueous layer in either case was aspirated directly for the determination of $\mathrm{Fe}, \mathrm{Cu}, \mathrm{Ni}$ and $\mathrm{Zn}$ by atomic absorption spectrophotometer Model Hitachi 180-50, using an air acetylene flame. The metal contents were calculated from the standard calibration curves, prepared by running a series of standard solutions of metal ions.

\subsection{Preparation of standard calibration curves}

Working standards of each metal were prepared from the certified standard solutions, provided by Fluka Chemicals, in freshly prepared $2 \mathrm{~N}$ nitric acid. A series of standard solutions of each metal ion in the range of absorbance noted for unknown samples were simultaneously run on the instrument under the same set of analytical conditions. Standard calibration curves were obtained for concentrations verses absorbance data that was statistically analyzed using fitting of straight line by least square method.

\subsection{Percent recovery test}

For percent recovery test, a double bleached, deodorized (citric acid treated) salad grade soybean oil sample was spiked with $1.0,0.75,0.50,0.25$, and $0.10 \mathrm{ug} / \mathrm{gm}$ of each of the metal ions and extracted and digested in the same manner as the sample. So, it experienced the same effect as the analyte. Percent recovery data was then calculated.

\section{RESULTS AND DISCUSSION}

In the present work, certain modifications made by us in the existing acid extraction procedure for the estimation of trace metals by AAS have shown better results in terms of percent recovery and time constraints. Particularly, the use of ultrasonic intensification for the extraction of metals, owing to vigorous speed and intensity, has proved very effective in the breaking of oil matrixes. Once the samples were ultrasonically intensified and extracted, the phase separation of the resulting mixtures, in a refrigerator had shown 30 minutes of equilibration sufficient for $91-96 \%$ recovery of trace metals. This might be attributed to a quick and better separation of aqueous and organic phases under cooling as compared with that of ambient equilibration and thus a good and rapid determination of the trace metals in the present analysis. After the analytical period of 30 minutes of equilibration, an over-night stayed did not produced significant increase in the results. Elson et al., (Elson et al., 1981) had also used refrigerator storage for phase separation during the extraction of heavy metals in Menhaden oil.

Further improvement was the use of centrifugation for phase separation, instead of equilibration, which had reduced the time incurred in equilibration under refrigeration, from 30 to only 2.5 minutes. Nonetheless, the percent recovery i.e., 93.6-101.2 of different metals was increased by the centrifugal mode of phase separation; the time had also been dramatically shortened to 2.5 minutes.

Table I shows statistical data for the calibration of standards of different metals by atomic absorption spectrophotometry. The data reveled excellent coefficient of correlation ranging from 0.9988 to 0.9994 within the concentration range of $0-1.0 \mathrm{ppm}$ for each metal ion. The working conditions of the instrument, used for the analysis of different metals 
Table I

Statistical Data For Standards of Elements

\begin{tabular}{lccccc}
\hline Elements & $\begin{array}{c}\text { Conc. range } \\
\text { ppm }(\mathrm{x})\end{array}$ & $\begin{array}{c}\text { Absorption range } \\
(\mathrm{Y})\end{array}$ & \multicolumn{3}{c}{$\begin{array}{c}\text { Statistical calculation } \\
\mathrm{Y}=\mathrm{mx}+\mathrm{c}\end{array}$} \\
\hline Iron & $\mathbf{0 . 0 - 1 . 0}$ & $0.0-\mathbf{0 . 0 9 0}$ & 0.0904 & 0.0003 & 0.9994 \\
Zinc & $\mathbf{0 . 0 - 1 . 0}$ & $0.0-0.193$ & 0.1940 & 0.0002 & 0.9990 \\
Copper & $0.0-1.0$ & $0.0-0.070$ & 0.0768 & 0.0002 & 0.9992 \\
Nickel & $0.0-1.0$ & $0.0-0.066$ & 0.0664 & 0.0003 & 0.9988 \\
\hline
\end{tabular}

Table II

Instrumental Conditions Used for the Analysis of Standards and Samples

\begin{tabular}{|c|c|c|c|c|c|c|c|c|c|}
\hline Elements & $\begin{array}{c}\text { Wave } \\
\text { length } \\
(\mathrm{nm})\end{array}$ & $\begin{array}{c}\text { Slit } \\
\text { width } \\
(\mathrm{nm})\end{array}$ & $\begin{array}{c}\text { Lamp } \\
\text { current } \\
(\mathrm{mA})\end{array}$ & $\begin{array}{l}\text { Fuel flow } \\
\text { (acetylene) } \\
\text { (I/min) }\end{array}$ & $\begin{array}{c}\text { Flow rate } \\
\text { (Air) } \\
\text { (I/min) }\end{array}$ & $\begin{array}{l}\text { Burner } \\
\text { height } \\
(\mathrm{mm})\end{array}$ & $\begin{array}{l}\text { Oxidant } \\
\text { (Air) } \\
\mathrm{kg} / \mathrm{cm}^{2}\end{array}$ & 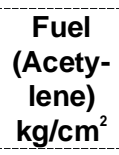 & $\begin{array}{l}\text { Signal } \\
\text { out put }\end{array}$ \\
\hline $\mathrm{Fe}$ & 248.5 & 0.2 & 7.5 & 2.30 & 9.41 & 7.5 & 1.60 & 0.3 & $100 \%$ \\
\hline $\mathrm{Zn}$ & 214 & 1.3 & 7.0 & 2.01 & 9.41 & 7.5 & 1.60 & 0.2 & $=$ \\
\hline $\mathrm{Cu}$ & 325.0 & 1.3 & $=$ & $=$ & $=$ & $=$ & $=$ & $=$ & $=$ \\
\hline $\mathrm{Ni}$ & 232.3 & 0.2 & 9.5 & $=$ & $=$ & 7.5 & $=$ & $=$ & $=$ \\
\hline
\end{tabular}

in samples and corresponding standards are given in Table II.

The data of standard addition test for iron, copper, nickel and zinc, using different sample preparation techniques coupled by atomic absorption spectrophotometric analysis, so far as their percentage recovery is concerned is shown in Table III. The results of the proposed acid-extraction method (method- $\mathrm{A}_{2}$ ), with in the concentration range of $0.10 \mathrm{ppm}-1.00 \mathrm{ppm}$ showed that the recovery of iron, copper, nickel and zinc ranged from 94.60 $98.00 \%, 93.60-100.40 \%, 95.00-97.30 \%$ and $96.00-100.20 \%$ respectively. These recovery ranges are in close agreement with those of the wet digestion method (Table 3).

The effect of different optimized parameters that influence the percent recovery of encountered trace metals is shown by three plots as represented by Fig 1-3. Figure 1 shows the effect of the intensification period on the determination of iron, copper, nickel and zinc in a typical banaspati ghee sample (Tul.Ba). It is clear from the plot that an intensification period of 7.0 minutes is sufficient for the optimum analysis of metals. Further intensification did not show any significant increase (1.5\%) in the recovery of metals. Figure 2 shows the effect of the equilibration period on the recovery of different trace metals. As evident from the plot of the figure, thirty minutes of equilibration in a refrigerator are found to be quite sufficient for the effective recovery and determination of metals and thus provided the most practical solution. Figure 3 shows the effect of the centrifugation period on the determination of metals. It is understandable from the plot that a centrifugation period of 2.5 minutes is enough for the determination of optimum amounts of the investigated metals as further centrifugation did not show any significant increase in the results.

The analytical or optimum concentration (maximum amount found under the above optimized conditions) of iron $0.57 \mathrm{ppm}$, copper $0.087 \mathrm{ppm}$, nickel $0.389 \mathrm{ppm}$ and zinc $0.048 \mathrm{ppm}$ in a typical banaspati (Tul. Ba), as determined by extractive method- $A_{2}$ is also in close agreement with those of the wet digestion method (see table IV). It is seen that approximately 10 minutes are more than sufficient for the extraction of virtually all nickel, iron, copper and zinc from the oil matrix, further treatment producing less than a 2 percent increase in the amount of metals extracted.

The concentration of different metals in some representative oils and fats as determined by the 
Table III

Data for Standard Addition Method for Different Metals

\begin{tabular}{|c|c|c|c|c|c|c|c|}
\hline \multirow{5}{*}{$\begin{array}{l}\text { Meta } \mathrm{s} \\
\mathrm{Fe}:\end{array}$} & \multirow{4}{*}{ Amount added iug/gn } & \multirow{2}{*}{\multicolumn{4}{|c|}{$\begin{array}{l}\text { A) Amount Found (ug/gm)" } \\
\text { Improved Acd Extraction }\end{array}$}} & \multirow{3}{*}{\multicolumn{2}{|c|}{ Wet Digestion }} \\
\hline & & & & & & & \\
\hline & & \multirow{2}{*}{$\begin{array}{l}\text { Method-A, } \\
\text { Mean }\end{array}$} & \multirow{2}{*}{\multicolumn{2}{|c|}{$\begin{array}{l}\text { Method }-A_{2} \\
\text { RSD }\end{array}$}} & \multirow[b]{2}{*}{ RSD * } & & \\
\hline & & & & & & Mer & an RSD' \\
\hline & & & & & & & \\
\hline & 1.00 & 0948 & 7.95 & 0.960 & 6.08 & 0.978 & 700 \\
\hline & 0.75 & 0712 & 7.86 & 0.727 & 7.00 & 0.736 & 649 \\
\hline & 0.50 & 0469 & 1004 & 0.473 & 9.21 & 0.480 & 800 \\
\hline & 0.25 & 0230 & 9.90 & 0245 & 1005 & 0254 & 12.00 \\
\hline & 0.10 & 0092 & 13.00 & 0.095 & 11.78 & 0.0971 & 1065 \\
\hline & $\%$ Pecovery & \multicolumn{2}{|c|}{ (92 00-94.80\%) } & \multicolumn{2}{|c|}{ (9460-98.00\%) } & \multicolumn{2}{|c|}{ (97 10-101,60\%) } \\
\hline \multicolumn{8}{|l|}{$\mathrm{Cu}$} \\
\hline & 1.00 & 0.937 & 685 & 0.958 & 5.00 & 0987 & 605 \\
\hline & 0.75 & 0.705 & 700 & 0.702 & 6.55 & 0728 & 560 \\
\hline & 0.50 & 0.462 & 10.00 & 0.502 & 7.00 & 0,480 & 8.00 \\
\hline & 0.25 & 0.228 & 970 & 0.236 & 8.40 & 0242 & 10.00 \\
\hline & 0.10 & 0.091 & 10.10 & 0.936 & 13.00 & 0965 & 12.65 \\
\hline & $\%$ Recovery & \multicolumn{2}{|c|}{$(91.40-93.98 \%)$} & \multicolumn{2}{|c|}{$(93.60-100.40 \%)$} & \multicolumn{2}{|c|}{ (96 50-98.80\%) } \\
\hline \multicolumn{8}{|l|}{ Ni: } \\
\hline & 1.00 & 0.930 & 6.15 & 0868 & 600 & 0980 & 705 \\
\hline & 0.75 & 0.710 & 7.00 & 0719 & 590 & 0734 & 6.00 \\
\hline & 0.50 & 0.465 & 1000 & 0475 & 800 & 0490 & 800 \\
\hline & 0.25 & 0.230 & 7.50 & 0239 & 705 & 0243 & 9.00 \\
\hline & 0.10 & 0.094 & 1500 & 0936 & 11.08 & 0100 & 12.00 \\
\hline & $\%$ Recovery & \multicolumn{2}{|c|}{ (92.18-94.60\%) } & \multicolumn{2}{|c|}{ (95.00-97.30\%) } & \multicolumn{2}{|c|}{$(97.25-100.00 \%)$} \\
\hline \multicolumn{8}{|l|}{$\mathbf{Z n}$} \\
\hline & 100 & 0950 & 6.15 & 0970 & 600 & 0.987 & 7.05 \\
\hline & 075 & 0719 & 7.00 & 0742 & 505 & 0.737 & 7.00 \\
\hline & 050 & 0480 & 8.90 & 0505 & 700 & 0.485 & 900 \\
\hline & 025 & 0234 & 10.50 & 0242 & 805 & 0.240 & 6.20 \\
\hline & 010 & 0093 & 15.00 & 0096 & 12.00 & 0.100 & 1500 \\
\hline & $\%$ Recovery & \multicolumn{2}{|c|}{$(9320-96.00 \%)$} & \multicolumn{2}{|c|}{ (96.00-101.20\%) } & \multicolumn{2}{|c|}{ (9600-98.70\%) } \\
\hline
\end{tabular}

three sample preparation methods is given in Table IV. A comparison of the results of these methods shows that the results of the proposed acid extractive method-- $\mathrm{A}_{2}$ do not show significant variation to those of the wet digestion method. From these results, it can be said that the agreement between these two methods is satisfactory. However, the contents of the investigated metals, as determined by the acid extractive method- $A_{1}$ are almost 1-3.5 \% below those values obtained by the proposed method- $A_{2}$. Although the decrease in the results of method-- $A_{1}$, probably due to incomplete phase separation, is not as significant as that of method $-\mathrm{A}_{2}$, the limitation of equilibration time of 30 minutes in the first method makes it inferior to the second method.

As the acid -extractive method-- $\mathrm{A}_{2}$ has been found very rapid, the time required for the 


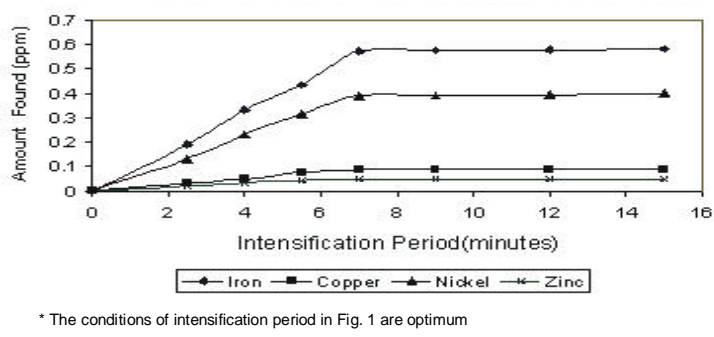

Figure 1

Effect of Intensification Period on the Determination of Different Metals in a Typical Ghee Sample (Tul.Ba)

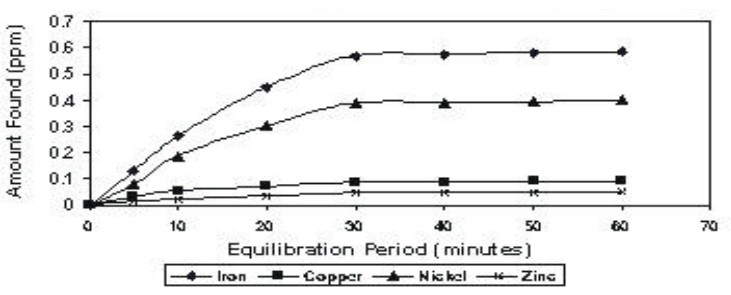

* The conditions of equilibration in Fig. 2 are optimum

Figure 2

Effect of equilibration Period on the Determination of Different Metals in a Typical Ghee Sample (Tul.Ba)

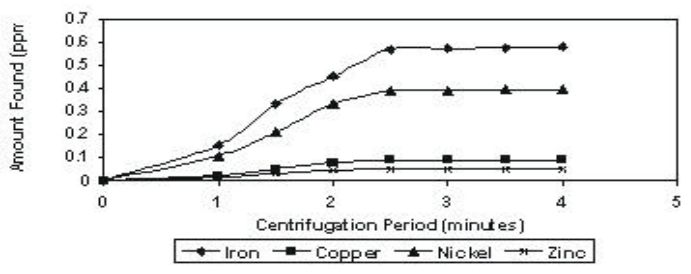

* The conditions of centrifugation periods in Fig. 3 are optimum

Figure 3

Effect of centrifugation Period on the Determination of Different Metals in a Typical Ghee Sample (Tul.Ba)

preparation of an oil sample for the AAS analysis is less than 10 minutes, and the results are also reproducible and quite comparable with the conventional wet digestion method. It could be possible to declare that our proposed method-- $\mathrm{A}_{2}$ is better than the tedious, time consuming wet digestion method and could be applied, appreciably, for the analysis of encountered trace metals in vegetable oil and fats over a wide range of applications.

The results of the analyses of different oils and fat products for $\mathrm{Fe}, \mathrm{Ni}, \mathrm{Cu}$ and $\mathrm{Zn}$, determined by the proposed method- $A_{2}$, under an optimized set of conditions are shown in Table V. A high iron content was found in most of the banaspati, which acts as a catalyzer and exhibits a noticeable catalytic effect in oil oxidation at very low concentrations. The overall content of iron in this category of product ranges from $0.130-1.982 \mathrm{ppm}$. Generally, the samples of non-reputable companies were quite high i.e., Rem. Ba 1.02 ppm, Ban. Ba 1.48 ppm and Naz. Ba 1.98 ppm, which may be due to the possible rusting of pipelines, tanks and reflects poor treatment in the handling of such products. The content of iron, which ranged from 0.409 to $2.48 \mathrm{ppm}$ in salad grade cooking oils, was even higher than that of banaspati samples. This may be attributed to the possible reaction between the relatively high-unsaturated portion of the oil with the surface of iron containers to be used during transportation, storage and processing of oils and fats. The amount of iron in shortening and margarine products ranged from $0.321-2.05 \mathrm{ppm}$, which is almost similar to the level in banaspati products. High levels of iron in most of the products may be due in part to poor operating and maintenance conditions in our industries. According to the reports (Smouse et al., 1994), for the best stability of oils, the level of iron should be below $0.1 \mathrm{ppm}$.

The content of copper in banaspati and salad grade oil samples was significantly high and ranged from 0.010 to $0.120 \mathrm{ppm}, \quad 0.013-0.114 \mathrm{ppm}$ respectively. The content of copper ranging from 0.028 -- $0.152 \mathrm{ppm}$ in shortening and margarine products was even higher than that of banaspati. Copper is the strongest prooxidant for oils, and for the best stability, the content of copper should be below 0.02 ppm (Smouse et al., 1994). The contamination of copper may be due to the degradation and deterioration of some metal alloys of iron equipment, being utilized for the treatment and purification of the oils.

The amount of Nickel (Ni) in Banaspati, and shortenings, margarine products ranging from 0.230 - $2.034 \mathrm{ppm}$, and 0.270 to $2.379 \mathrm{ppm}$ respectively was significantly high. The level of $\mathrm{Ni}$ in most of the cooking oils, except a few samples, was found to be quite low. The presence of a small amount of nickel in cooking oils may be attributed to the possible contamination of the traces of nickel from pipelines and reaction vessels of industrial equipment. A high magnitude of occurrence of $\mathrm{Ni}$, in the fat products of most of the non-reputed companies was in part due to poor filtration and post treatments of the hydrogenated oil stock. Hydrogenated oils require a post treatment to remove the residual nickel soaps prior to final filtration, which is cost effective and therefore is usually skipped by industries. The presence of nickel in hydrogenated oils and fats is important from a health and safety standpoint (Nigro, 1980), and the recommended safe limit for the end-use commercial banaspati products of Pakistan is less than $0.50 \mathrm{ppm}$ (PSI, 1991). The presence of nickel in most of the fat products above safe limits, clearly, reflected the careless processing of oils and fats by the manufacturers as well as the negligence 
Table IV

Comparison of Sample Preparation Methods for the Analysis of Trace Metals in Typical Oil and Fats Products as Determined by AAS (ppm) ${ }^{\mathrm{a}}$

\begin{tabular}{|c|c|c|c|c|}
\hline Metal & Oil/Fat Sample & $\frac{\text { Improved }}{\text { Method-A }}$ & $\frac{d \text {-Extraction }}{\text { Method- } A_{2}}$ & $\begin{array}{l}\text { Wet Digestion } \\
\text { (Method-B) }\end{array}$ \\
\hline \multicolumn{5}{|l|}{ Iron (Fe) } \\
\hline & Tul. Ba & $0.559 \pm 0.05$ & $0.570 \pm 0.06$ & $0.600 \pm 0.05$ \\
\hline & Dal. Ba & $0.460 \pm 0.03$ & $0.468 \pm 0.04$ & $0.479 \pm 0.06$ \\
\hline & Sos. Co & $0.180 \pm 0.06$ & $0.186 \pm 0.04$ & $0.190 \pm 0.03$ \\
\hline & Hab. Co & $0.978 \pm 0.05$ & $1.060 \pm 0.07$ & $1.050 \pm 0.06$ \\
\hline & Pkb. Ma & $0.965 \pm 0.04$ & $1.002 \pm 0.06$ & $1.049 \pm 0.05$ \\
\hline \multicolumn{5}{|c|}{ Copper (Cu) } \\
\hline & Tul. Ba & $0.086 \pm 0.005$ & $0.087 \pm 0.005$ & $0.090 \pm 0.006$ \\
\hline & Dal. Ba & $0.053 \pm 0.005$ & $0.054 \pm 0.006$ & $0.057 \pm 0.004$ \\
\hline & Sos. Co & $0.024 \pm 0.006$ & $0.023 \pm 0.005$ & $0.025 \pm 0.006$ \\
\hline & Hab. Co & $0.055 \pm 0.007$ & $0.060 \pm 0.005$ & $0.059 \pm 0.004$ \\
\hline & Pkb. Ma & $0.106 \pm 0.003$ & $0.105 \pm 0.006$ & $0.110 \pm 0.005$ \\
\hline \multicolumn{5}{|l|}{ Nickel (Ni) } \\
\hline & Tul. Ba & $0.390 \pm 0.006$ & $0.389 \pm 0.05$ & $0.410 \pm 0.04$ \\
\hline & Dal. Ba & $0.289 \pm 0.05$ & $0.300 \pm 0.03$ & $0.310 \pm 0.06$ \\
\hline & Sos.Co & $0.038 \pm 0.005$ & $0.041 \pm 0.004$ & $0.041 \pm 0.004$ \\
\hline & Hab. Co & $0.059 \pm 0.005$ & $0.065 \pm 0.003$ & $0.064 \pm 0.006$ \\
\hline & Pkb.Ma & $1.090 \pm 0.04$ & $1.096 \pm 0.03$ & $1.150 \pm 0.05$ \\
\hline \multicolumn{5}{|c|}{ Zinc (Zn) } \\
\hline & Tul. Ba & $0.046 \pm 0.003$ & $0.048 \pm 0.004$ & $0.050 \pm 0.003$ \\
\hline & Dal. Ba & $0.137 \pm 0.005$ & $0.140 \pm 0.004$ & $0.150 \pm 0.004$ \\
\hline & Sos. Co & $0.065 \pm 0.006$ & $0.069 \pm 0.005$ & $0.071 \pm 0.005$ \\
\hline & Hab. Co & $0.065 \pm 0.005$ & $0.070 \pm 0.006$ & $0.070 \pm 0.007$ \\
\hline & Pkb.Ma & $0.059 \pm 0.004$ & $0.058 \pm 0.005$ & $0.062 \pm 0.005$ \\
\hline
\end{tabular}

Method $-A_{A}=$ Samples prepared by ultrasonic intensification followed by equilibration as analyzed by AAS

Method $-\mathrm{A}_{2}=$ Samples prepared by ultrasonic intensification followed by centrifugation as analyzed by AAS

${ }^{a}$ Values (mean $\pm S D$ ) are average of three samples of each brand analyzed in triplicate

of the quality monitoring agencies in Pakistan. The content of zinc in most of the oil or fat samples was almost equal to the investigated copper content of the products and may be attributed to the same reasons as the contamination of copper.

\section{CONCLUSION}

Trace quantities of some metals are naturally present in oilseeds, and crude oil is extracted from them. The biological pattern of cultivation and the status of the processing equipment, vary from oil or fat manufacturing unit to unit. So, it is hard to conclude in absolute terms what would be the exact level of such metallic contaminants in raw and end-use products. However, it could be possible to determine reliable data for different encountered trace metals with the help of precise and accurate analytical methods. The contamination of prooxidants and toxic metals in such products may be kept to a minimum level, with proper treatment and handling of oils and fats e.g., pretreatment with phosphoric acid and effective purification during refining and bleaching, citric acid treatment after deodorization and fine filtration after post treatments etc. It could not be completely possible to eliminate the contact of oils with iron because most of the industries use black iron equipment. The use of stainless steel, 304 S.S, 316 S.S sheets for the fabrication of oil containers, reactors and other operational vessels,

Method- $A_{1}=$ Sample prepared by ultrasonic intensification followed by equilibration as analyzed by AAS

Method- $A_{2}=$ Sample prepared by ultrasonic intensification followed by centrifugation as analyzed by AAS

a Values (mean $\pm S D$ ) are average of three samples of each brand analyzed in triplicate 
Table V

Metal contents (ppm) $)^{\mathrm{a}}$ of Different Oil and Fat Products as Determined by Proposed Acid Extractive Method $-\mathrm{A}_{2}$

\begin{tabular}{|c|c|c|c|c|}
\hline Oil/Fat Sample & Iron & Copper & Nickel & Zinc \\
\hline Ksn. Ba & $0.470 \pm 0.03$ & $0.032 \pm 0.003$ & $0.392 \pm 0.03$ & $0.074 \pm 0.004$ \\
\hline Dat.Ba & $0.241 \pm 0.06$ & $0.060 \pm 0.004$ & $0.492 \pm 0.03$ & $0.103 \pm 0.006$ \\
\hline Shn.Ba & $0.692 \pm 0.05$ & $0.052 \pm 0.003$ & $2.034 \pm 0.05$ & $0.082 \pm 0.007$ \\
\hline Sos.Ba & $0.132 \pm 0.060$ & $0.010 \pm 0.003$ & $0.230 \pm 0.04$ & $0.037 \pm 0.003$ \\
\hline Sez.Ba & $0.421 \pm 0.05$ & $0.020 \pm 0.003$ & $0.192 \pm 0.03$ & $0.050 \pm 0.004$ \\
\hline Rem.Ba & $1.020 \pm 0.005$ & $0.100 \pm 0.002$ & $1.956 \pm 0.05$ & $0.088 \pm 0.004$ \\
\hline $\mathrm{Hab} . \mathrm{Ba}$ & $0.509 \pm 0.04$ & $0.063 \pm 0.005$ & $0.399 \pm 0.04$ & $0.103 \pm 0.004$ \\
\hline Ban.Ba & $1.480 \pm 0.05$ & $0.092 \pm 0.004$ & $0.780 \pm 0.06$ & $0.05 \pm 0.005$ \\
\hline $\mathrm{Naz} \cdot \mathrm{Ba}$ & $1.982 \pm 0.04$ & $0.120 \pm 0.004$ & $1.472 \pm 0.04$ & $0.097 \pm 0.005$ \\
\hline \multicolumn{5}{|l|}{ Cooking Oils } \\
\hline Tul. CO & $0.541 \pm 0.04$ & $0.037 \pm 0.006$ & $0.027 \pm 0.002$ & $0.063 \pm 0.005$ \\
\hline Tulg.CO & $1.571 \pm 0.05$ & $0.059 \pm 0.004$ & $0.1210 \pm 0.003$ & $0.092 \pm 0.004$ \\
\hline Dal. CO & $0.409 \pm 0.03$ & $0.063 \pm 0.005$ & $0.199 \pm 0.004$ & $0.120 \pm 0.010$ \\
\hline Dal.SFO & $0.674 \pm 0.05$ & $0.038 \pm 0.004$ & $0.082 \pm 0.005$ & $0.064 \pm 0.010$ \\
\hline Sez. CCO & $0.438 \pm 0.04$ & $0.013 \pm 0.003$ & $0.317 \pm 0.005$ & $0.043 \pm 0.005$ \\
\hline $\mathrm{Hab}$ CCO & $0.870 \pm 0.04$ & $0.063 \pm 0.005$ & $0.420 \pm 0.004$ & $0.102 \pm 0.007$ \\
\hline Ba. CO & $2.481 \pm 0.05$ & $0.114 \pm 0.004$ & $0.207 \pm 0.005$ & $0.097 \pm 0.003$ \\
\hline Ree.CO & $1.08 \pm 0.06$ & $0.050 \pm 0.004$ & $0.108 \pm 0.007$ & $0.117 \pm 0.006$ \\
\hline \multicolumn{5}{|l|}{ Shortenings } \\
\hline Tuli.Sh & $0.282 \pm 0.0340$ & $0.039 \pm 0.006$ & $0.587 \pm 0.04$ & $0.063 \pm 0.005$ \\
\hline Chi.Sh & $1.213 \pm 0.057$ & $0.090 \pm 0.006$ & $1.971 \pm 0.08$ & $0.117 \pm 0.007$ \\
\hline Bmp.Sh & $0.379 \pm 0.04$ & $0.037 \pm 0.005$ & $0.421 \pm 0.04$ & $0.092 \pm 0.005$ \\
\hline Bmc.Sh & $0.835 \pm 0.03$ & $0.062 \pm 0.005$ & $2.379 \pm 0.102$ & $0.073 \pm 0.004$ \\
\hline Bmb.Sh & $0.524 \pm 0.05$ & $0.137 \pm 0.01$ & $0.931 \pm 0.07$ & $0.203 \pm 0.0065$ \\
\hline Puf.Sh & $0.321 \pm 0.04$ & $0.028 \pm 0.005$ & $0.476 \pm 0.04$ & $0.053 \pm 0.006$ \\
\hline Rbl.Sh & $0.343 \pm 0.03$ & $0.102 \pm 0.010$ & $1.562 \pm 0.09$ & $0.098 \pm 0.0007$ \\
\hline \multicolumn{4}{|l|}{ Margarines } & $0.097 \pm 0.008$ \\
\hline Blb.Ma & $0.372 \pm 0.07$ & $0.042 \pm 0.004$ & $0.732 \pm 0.05$ & $0.063 \pm 0.007$ \\
\hline Pkb.Ma & $0.821 \pm 0.06$ & $0.103 \pm 0.009$ & $0.470 \pm 0.04$ & $0.213 \pm 0.010$ \\
\hline Bak-1Ma & $1.232 \pm 0.04$ & $0.099 \pm 0.01$ & $1.831 \pm 0.03$ & $0.137 \pm 0.020$ \\
\hline Soft $-1 \mathrm{Ma}$ & $2.433 \pm 0.05$ & $0.152 \pm 0.007$ & $0.531 \pm 0.06$ & $0.052 \pm 0.004$ \\
\hline Bak-2 Ma & $0.689 \pm 0.06$ & $0.092 \pm 0.006$ & $0.298 \pm 0.03$ & $0.100 \pm 0.009$ \\
\hline
\end{tabular}

Ba. Banaspati, Sh. Shortening, CO Cooking oil, CCO Canola Cooking Oil, SFO Sun Flower Oil,

FO Frying Oil, Ma Margarine

${ }^{a}$ Values (mean $\pm \mathrm{SD}$ ) are average of three samples of each brand analyzed in triplicate 
and as well as their cleanliness may help keep the contamination of such metals to an extremely low level.

\section{ACKNOWLEDGEMENT:}

The author would like to express special thanks for Dr. Razia Sultana, Senior Scientific Officer, Applied Chemistry Research Center of PCSIR laboratories Complex, Karachi, Pakistan, for her kind help and support during the compilation of this manuscript.

\section{REFERENCES:}

Allens, L. B., Siitonen, P. H., Thompson, H. C. (1998). Determination of copper, lead and nickel in edible oils by plasma and furnace atomic spectroscopies. J. Am. Oil Chem. Soc., 75 (4), 477-481.

Anwar, F., Bhanger, M. I., Kazi, T. G., Saleem, Y. (2001). An improved sample preparation method for the determination of trace metals in vegetable oils and commercial fats by atomic absorption spectrophotometers. 92 ${ }^{\text {nd }}$ AOCS Annual Meeting and Expo, Minneapolis, Minnesota, May 13-16, Abstracts (A special supplements to Inform) p. S7.

Anzan, J. M., Gonzalez, P. (2000). Determination of iron and copper in peanuts by flam atomic absorption spectroscopy using acid digestion. Microchem. J., 64 (2), 141-145.

Black, L.T., (1975). Comparison of three atomic absorption techniques for the determination of metals in soybean oil. J. Am. Oil Chem., 52 (3), 88-91.

Chen, S. R., Chen, C.M., Chen, C. C., Chou, S.S. (1999). Determination of copper in edible oils by direct graphite furnace atomic absorption spectroscopy. Yaowu Shipin Fenixi, 7 (3), 207-214.

Chmilenko, F.A., Bablansi, L.V. (1998). Atomic absorption determination of toxic elements in fats and oils. Lib. Khim. Zh., 64, (1-2), 134-140.

Elson, C.M., Bremer, E.M., Ackman, R. G. (1981). Determination of heavy metals in Menhaden oil after refining and hydrogenation using several analytical methods. J. Am. Oil Chem. Soc., 58 (12), 1024 -1026.

Flider, F. J., Orthoefer, F. T. (1981). Metals in Soybean oil. J. Am. Oil. Chem. Soc., 58 (3), 270-272.
Hammond, G.W., Shiers, V.P., Rossell, J.B. (1999). Atomic spectroscopy for heavy metal determination in edible oils and fats. in Spectral Properties of. Lipids, pp.20-48. $\mathrm{R} J$ J. Hamilton and J Cast (Eds). Blackwell Publishing

Ivanov, S., Ivanov, K., Maneva, D. (1994). Differently bonded heavy metals in lipids and a method for their differentiated determination. SOFW J., 120 (8), 450-452.

Ivanov, K., Panchev, I. (1995). An investigation into the dependence between the contents of the different ionic forms of heavy metals in lipids and their pro-oxidative effects. Z. Lebensm. Unters. Forsch. 201 (3), 218-220.

Marfec, A., Bulinski, R. (1997). Content of some trace elements in nuts and edible seeds, Bromatol. Chem. Toksykol, 30 (2), 125-128.

McGinley, L. (1991). Quality Control for Processing and Processed Fats in Analysis of Oilseeds, Fats and fatty Foods, p. 480-481. J. B. Rossell \& J. L. R. Pritchard (Eds.), Elsevier Science Publishers Ltd., New York, London.

Nigro, J.A., (1980). Nickel in the Environment, Wiley, New York.

Pakistan Standard Institute (PSI), (1990). Specifications of Cooking Oils, PSI Specification No. 2.858, Sadar, Karachi, Pakistan.

Persmers, U., Toregrand, B. (1971). Metal analysis of edible fats and oil by atomic absorption spectroscopy. J. Am. Oil Chem. Soc., 48, 650-652.

Price, W. J., Roos, J. T. H., Clay, A. F. (1970). Rapid determination of Nickel in edible fats by Atomic absorption spectrophotometry. Analyst, 95, 760-762.

Sleeters, R. T. (1985). Bailey's Industrial Oil and Fats products, Vol. 3, p. 167-242. T.H. Apple white, (Ed.), John Wiley, Chichester.

Smouse, T.H., (1994). Factors Affecting Oil Quality and Stability in Methods to Assess Oil Quality and Stability of Oils and Fat-Containing Foods. p. 17-36. K.Warner and N.A.M. Eskin (Eds.), AOCS, Champaign.

Yaman, M., Gucer, S.(1998). Determination of Nickel in vegetable matrixes by atomic absorption spectrometry after preconcentration on activated carbon, Ann. Chim. 88 (7-8), 565-565. 